\title{
Effects of darbepoetin alfa and epoetin beta pegol on iron kinetics in hemodialysis patients
}

\author{
Jun Sawa ${ }^{1 *}$, Masaaki Inaba ${ }^{2,3}$, Koichi Noguchi', Chie Nakagawa', Mayuko Kuwamura', Yukinobu Kuwamura', \\ Noritsugu Wada ${ }^{1}$, Kayoko Kitatani ${ }^{1}$, Yuji Kawaguchi ${ }^{1}$ and Yasuro Kumeda ${ }^{1}$
}

\begin{abstract}
Background: Erythropoiesis-stimulating agents, for example epoetin beta pegol which is a continuous erythropoietin receptor activator (CERA), and darbepoetin alfa (DPO), are recently introduced into clinical practice for the treatment of anemia in hemodialysis patients. Here, we compared the effects of CERA and DPO on erythropoiesis and iron kinetics in hemodialysis patients.
\end{abstract}

Methods: In this open label, single arm trial, after $40 \mu \mathrm{g} /$ week of DPO administration, $75 \mu \mathrm{g} / 2$ weeks of CERA was administered during 14 days in 7 hemodialysis patients without clinically overt inflammation or infection. Serum parameters of erythropoietic activity (hemoglobin) and iron kinetics (hepcidin-25 [hepcidin], ferritin, high-sensitivity C-reactive protein and transferrin saturation [TSAT]) were evaluated during the study periods.

Results: DPO significantly increased the hemoglobin levels above the baseline, as compared to the insignificant increase by CERA. Suppression of serum ferritin was more significant during CERA than DPO $(P=0.018)$, while TSAT or serum hepcidin did not differ significantly between CERA and DPO (TSAT, $P=0.866$; hepcidin, $P=0.063$ ). Our results suggested that, under conditions indicating a significantly weaker effect of CERA than DPO on erythroblastosis, the greater suppression of serum ferritin by CERA might indicate its potent effect on iron utilization.

Conclusions: The effect of CERA administered once every 2 weeks exhibited no less potent effect in terms of iron utilization than that of DPO administered every week.

Keywords: Darbepoetin alfa, Epoetin beta pegol, Ferritin, Hepcidin, Transferrin saturation, Hemoglobin, Iron utilization, Hemodialysis

\section{Background}

Erythropoiesis-stimulating agents (ESAs), such as recombinant human erythropoietin (rHuEPO), darbepoetin alfa (DPO), and epoetin beta pegol (continuous erythropoietin receptor activator; CERA) are widely used in current clinical practice for the treatment of anemia in hemodialysis patients. Because of the different halflives of these ESAs in circulation after intravenous administrations (rHuEPO, $8.5 \mathrm{~h}$; DPO, $25.3 \mathrm{~h}$; CERA, approx. $130 \mathrm{~h}$ ), an appropriate administration regimen for each agent should be determined [1]. For example,

\footnotetext{
* Correspondence: junpeach43358@yahoo.co.jp

${ }^{1}$ Department of Internal Medicine, Minami-Osaka Hospital, Osaka, Japan Full list of author information is available at the end of the article
}

while shorter-acting rHuEPO and longer-acting DPO are administered thrice and once a week, respectively [2], the longest-acting CERA is conventionally administered once every 2 or 4 weeks [3]. To enable more stabilized hemoglobin levels after switching the erythropoiesisstimulating agent (ESA) from weekly administration of DPO to CERA, it is strongly recommended to administer CERA every 2 weeks [4]. We have recently reported that longer-acting DPO might increase the utilization of iron from the body store more for bone marrow erythropoiesis in terms of its greater suppression of serum hepcidin while maintaining TSAT $>20 \%$ than shorteracting rHuEPO [5]. According to the 2008 Japanese Society for Dialysis Therapy: Guidelines for renal anemia 
in chronic kidney disease [6], as long as TSAT is maintained $>20 \%$, iron supplementation should be stopped when the serum ferritin level increases $\geq 100 \mathrm{ng} / \mathrm{mL}$ [5]. Due to the recent development of a precise assay for hepcidin [7], the serum level of hepcidin has been recognized as a relevant indicator for iron utilization for erythropoiesis [8]. Metabolism of hepcidin is tightly regulated by erythroferrone produced by erythroblasts, which increases as the erythropoietic activity of the bone marrow becomes elevated [9].

In the present study, we compared the effects of DPO administered once per week with those of CERA once every 2 weeks on iron kinetics and erythropoiesis in Japanese hemodialysis patients in an open label, single arm trial design during the total study period of 4 weeks.

\section{Methods}

\section{Patients}

All patients provided informed consent to participate in the study after being individually explained the study protocol and associated risks. The present study protocol was approved by the Ethical Committee of Social Care Corporation at Keigakukai South Osaka Hospital (2014-4).

The inclusion criteria were a clinically stable condition particularly in terms of hemoglobin $(\mathrm{Hb})$ levels and the dose of rHuEPO, as well as iron metabolism for 3 months before the start of the present study. All enrolled patients had received $\mathrm{rHuEPO}$ (3000 $\mathrm{IU} \times 3 /$ week) for more than 3 months prior to enrolment, had stable hemoglobin levels $(10.0-12.0 \mathrm{~g} / \mathrm{dL}$; variation $<0.5 \mathrm{~g} / \mathrm{dL}$ in the three months prior to enrolment), and transferrin saturation (TSAT) $>20 \%$ and serum ferritin $>50 \mathrm{ng} / \mathrm{mL}$.

Patients who are smokers and have other conditions likely to affect $\mathrm{Hb}$ levels, such as acute inflammation, infection, or cardiovascular disease, were excluded from the study. Acute inflammation and infection were defined by the presence of symptoms together with a serum C-reactive protein (CRP) level above the upper limit of normal of $0.4 \mathrm{mg} / \mathrm{dL}$. The presence of cardiovascular disease was evaluated based on clinical information regarding coronary, cerebral and peripheral artery diseases, and aortic aneurysm. Coronary artery disease was diagnosed when a subject had one or more of the following criteria: (1) past history of percutaneous coronary intervention or coronary artery bypass grafting, (2) presence of significant stenosis by coronary angiography, (3) presence of ST-T abnormalities on electrocardiogram associated with typical symptoms attributable to angina pectoris, and (4) use of one or more medication for coronary ischemia, as we have described previously [10]. None of the patients were iron-deficient on the basis of the absence of anemia and normal erythropoietin responsiveness index. Patients with evidence for marked inflammation or infection were excluded.

\section{Study design}

Seven outpatients (three male and four female), who had received maintenance hemodialysis for at least 6 months at Minami-Osaka Dialysis Clinic (Osaka, Japan), were enrolled in the study. The design of this open label, single arm trial is as follows. At the beginning of the study, rHuEPO (3000 IU × 3/week) was first continuously administered for 3 months and then withdrawn for a washout period of 7 days. Weekly DPO administration was then initiated for 14 days (administered weekly on days 0 and 7 at a dose of $40 \mu \mathrm{g} /$ week), which was immediately followed by $\mathrm{rHuEPO}$ administration for 4 weeks (3000 $\mathrm{IU} \times 3 /$ week). After $\mathrm{rHuEPO}$ administration was again stopped for a washout period of 1 week, CERA was administered once on day 0 at a dose of $75 \mu \mathrm{g}$ without any administration of ESA for the subsequent 14 days.

During the two 14-day treatment periods with DPO and CERA, biochemical parameters for bone marrow erythropoiesis and iron metabolism were monitored. No drugs that might affect erythropoietic activity or iron utilization were administrated during the study period. Hemoglobin level and serum parameters of iron metabolism (TSAT, serum ferritin and serum hepcidin) were measured immediately before ESA administration and also before the start of the hemodialysis session on days $0,2,4,7,9,11$, and 14 during the treatment periods with DPO and CERA. Serum high-sensitivity C-reactive protein level (hs-CRP) was measured on days 0,7 , and 14 . Utilization of iron was evaluated based on the area under the serum concentration-time curves of TSAT, serum ferritin, and serum hepcidin during the administration periods.

\section{Blood samples and determination of serum markers}

Blood samples were collected, kept on ice for $1 \mathrm{~h}$, centrifuged at $1000 \times g$ for $10 \mathrm{~min}$, aliquoted, and then stored at $-80{ }^{\circ} \mathrm{C}$ until assay. Serum hepcidin level was quantified by liquid chromatography tandem mass spectrometry (LCMS/MS) [7]. Serum ferritin was measured with a solid phase two-site chemiluminescence immunometric assay (Abbott Japan, Tokyo, Japan). Serum iron and total ironbinding capacity (TIBC) were determined using the bathophenanthroline method (Wako Pure Chemical Industries Ltd, Osaka, Japan). TSAT was calculated as serum iron $(\mu \mathrm{g} / \mathrm{dL}) / \mathrm{TIBC}(\mu \mathrm{g} / \mathrm{dL}) \times 100(\%)$. Serum hs-CRP level was determined with a latex turbidimetric immunoassay using an N-Assay LA CRP-S D-Type kit (Nittobo Medical, Tokyo, Japan).

Serum ferritin, hepcidin, hemoglobin, hs-CRP, and TSAT are parameters of renal anemia and therefore representatives of iron kinetics. Hence, we assessed the changes in their levels during the study period, and intergroup comparisons were performed between the two administration periods. The degree of suppression in serum ferritin, TSAT, 
and serum hepcidin level during the study period was then estimated.

\section{Statistical analyses}

Values are expressed as the mean \pm standard deviation (SD). Changes in serum biomarkers in addition to the relative changes of serum ferritin, TSAT, and hepcidin were compared during the DPO and CERA administration periods using the Wilcoxon signed-rank test due to the small number of patients in the present study.

The areas under the serum concentration-time curves (AUC) of ferritin, TSAT, and hepcidin were estimated by the trapezoidal rule and analyzed with the Wilcoxon signed-rank test.

The AUC was calculated based on the area between each curve and value at day 0 during the observation period from the data illustrated in Fig. 1 . Since the AUC was obtained in each patient with the conversion of AUC expressed in value $x$ days, SDs were obtained for TSAT, ferritin, and hepcidin.
A $P$ value $<0.05$ was considered to be significant. StatView version 5.0.1 software (SAS Institute Inc, Cary, NC) was used for the statistical analyses.

\section{Results}

\section{Patient characteristics}

The baseline characteristics of the patients enrolled in the study are shown in Table 1 . No significant difference was found in hemoglobin, serum iron, serum ferritin, TSAT, hepcidin, hs-CRP, albumin, body weight, or $\Delta$ body weight between DPO and CERA administration (Table 1).

\section{Changes in serum parameters for erythropoiesis and iron metabolism during DPO or CERA administration}

As shown in Fig. 1a, DPO administration significantly increased the hemoglobin level from $10.5 \pm 0.34$ to 10.9 $\pm 0.34 \mathrm{~g} / \mathrm{dL}(P=0.034)$, while CERA administration did not significantly affect the hemoglobin level during the treatment period of 14 days. Furthermore, hemoglobin level was significantly higher on day 11 during DPO

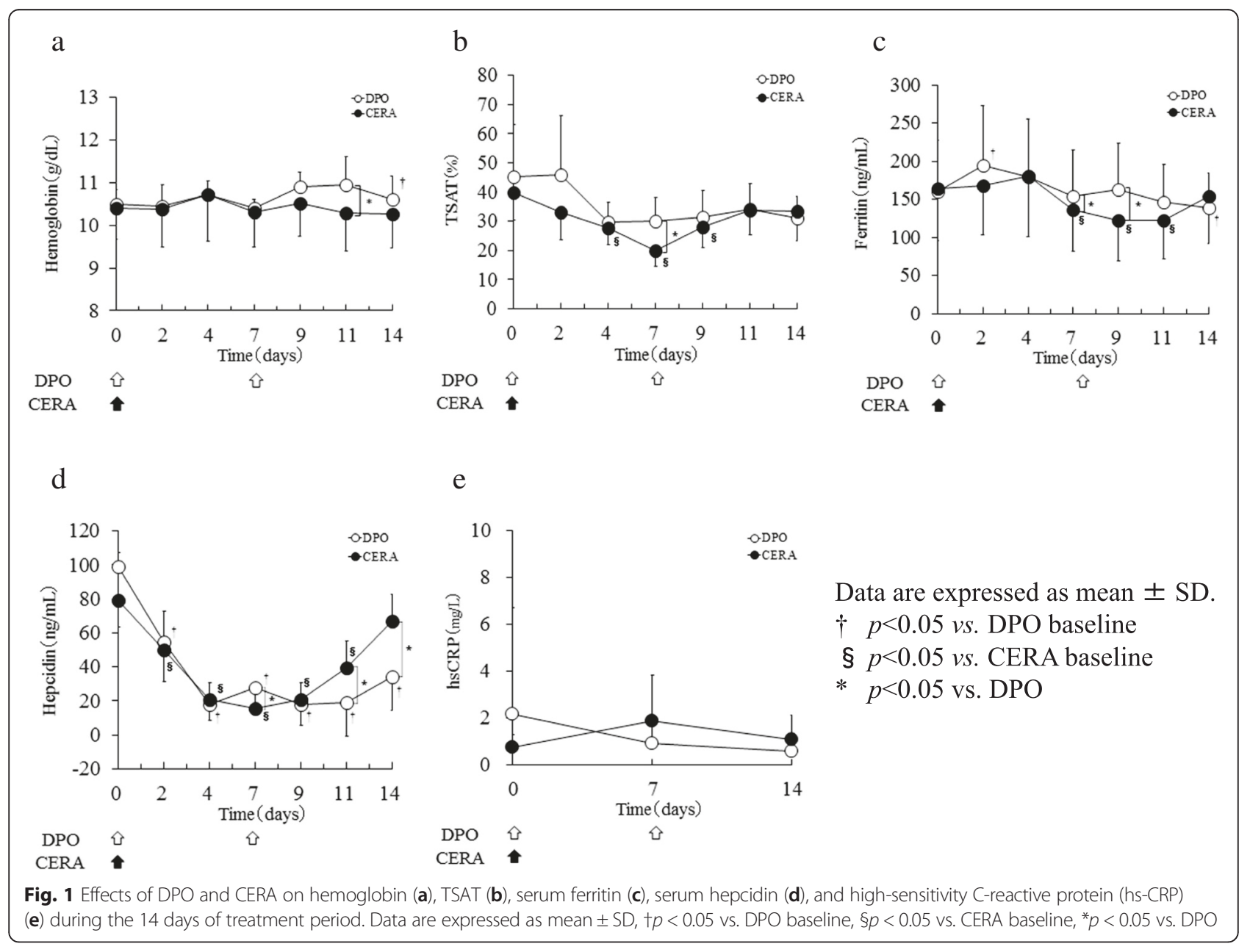


Table 1 Baseline characteristics of patient subjects at the start of DPO CERA treatment

\begin{tabular}{llll}
\hline & At the time of DPO treatment & At the time of CERA treatment & $P$ value \\
\hline Hemoglobin $(\mathrm{g} / \mathrm{dL})$ & $10.5 \pm 0.34$ & $10.4 \pm 0.75$ & 0.799 \\
Serum iron $(\mu \mathrm{g} / \mathrm{dL})$ & $82.4 \pm 26.34$ & $89.3 \pm 26.62$ & 0.447 \\
Serum ferritin $(\mathrm{ng} / \mathrm{mL})$ & $160.69 \pm 66.84$ & $163.67 \pm 67.40$ & 0.612 \\
TSAT $(\%)$ & $45.3 \pm 17.82$ & $39.8 \pm 9.44$ & 0.311 \\
Hepcidin $(\mathrm{ng} / \mathrm{mL})$ & $98.9 \pm 35.42$ & $79.3 \pm 27.95$ & 0.176 \\
hs-CRP $(\mathrm{mg} / \mathrm{dL})$ & $0.19 \pm 6.81$ & $0.07 \pm 5.01$ & 0.112 \\
Albumin $(\mathrm{g} / \mathrm{dL})$ & $3.5 \pm 0.29$ & $3.7 \pm 0.22$ & 0.106 \\
Body weight $(\mathrm{kg})$ & $57.9 \pm 5.2$ & $58.2 \pm 5.0$ & 0.229 \\
$\Delta$ Body weight $(\mathrm{kg})^{a}$ & $0.07 \pm 0.45$ & $0.30 \pm 0.56$ & 0.501 \\
\hline
\end{tabular}

$\operatorname{Sex}(\mathrm{M} / \mathrm{F}, n)$ is $3 / 4$

The age (years) is $72.3 \pm 7.63$

The hemodialysis duration (months) is $66.9 \pm 60.9$

${ }^{\mathrm{a}}$ Is the change of body weight during the 14 days of DPO and CERA treatment

administration than CERA administration $(10.9 \pm 0.66$ vs. $10.3 \pm 0.89 \mathrm{~g} / \mathrm{dL}, P=0.018)$. However, hemoglobin levels did not significantly differ between DPO and CERA administrations on day 0 and day 14 .

While DPO administration did not noticeably change TSAT during the treatment period of 14 days, CERA administration significantly suppressed TSAT in a progressive time-dependent manner from day 0 up to day 7 (day $0,39.8 \pm 9.44 \%$ vs. day $4,27.8 \pm 5.84 \%, P=0.018$; vs. day $7,19.8 \pm 5.48 \%, P=0.018)$ and remained suppressed on day $9(28.1 \pm 7.33 \%, P=0.028)$. TSAT was significantly lower on day 7 during CERA administration than DPO administration (Fig. 1b).

While DPO administration suppressed serum ferritin initially on day 14, CERA administration significantly suppressed serum ferritin from the baseline value of $163.7 \pm 67.4$ to $136.0 \pm 54.2 \mathrm{ng} / \mathrm{mL}$ on day $7(P=0.018)$, $122.1 \pm 53.0 \mathrm{ng} / \mathrm{mL}$ on day $9(P=0.018)$ and $122.7 \pm$ $51.1 \mathrm{ng} / \mathrm{mL}$ on day $11(P=0.018)$. Serum ferritin level significantly decreased during CERA administration than DPO administration on day $7(136.0 \pm 54.2$ vs. $154.5 \pm 60.0 \mathrm{ng} / \mathrm{mL}, P=0.043)$ and day $9(122.1 \pm 53.0$ vs. $163.5 \pm 59.9 \mathrm{ng} / \mathrm{mL}, P=0.018$ ) (Fig. 1c).

Serum hepcidin level was significantly suppressed by day 2 after the start of either DPO or CERA administration. However, serum hepcidin began to increase towards the normal baseline by day 11 during CERA treatment, whereas DPO maintained the suppression of serum hepcidin during the treatment period of 14 days, with serum hepcidin levels being significantly lower on days 11 and 14 during DPO administration than CERA administration. Serum hepcidin level was significantly suppressed during CERA administration than DPO administration on day 7 $(15.6 \pm 11.7$ vs. $27.8 \pm 11.3 \mathrm{ng} / \mathrm{mL}, P=0.028)$, whereas serum hepcidin level significantly was suppressed during DPO administration than CERA administration on day 11 $(18.9 \pm 19.8$ vs. $39.7 \pm 15.6 \mathrm{ng} / \mathrm{mL}, P=0.028)$ and day 14
(34.0 \pm 19.7 vs. $66.7 \pm 16.0 \mathrm{ng} / \mathrm{mL}, P=0.028)$ (Fig. 1d). In contrast, serum hs-CRP level did not change significantly during DPO or CERA administration (Fig. 1e).

Suppression of parameters of iron utilization during DPO and CERA administration

Figure 2 shows the effects of DPO and CERA suppression on TSAT (a), ferritin (b), and hepcidin (c), which were estimated from the area under the respective curve during the 14 days of treatment. As shown in Fig. 2b, the suppression of serum ferritin was significantly greater during CERA administration than DPO administration (CERA vs. DPO; $220.6 \pm 284.56$ vs. $-36.0 \pm 295.01 \mathrm{ng} / \mathrm{mL}^{*}$ day; $\left.P=0.018\right)$. As shown in Fig. 2a, c, the suppressions of TSAT (CERA vs. DPO; $P=0.866$ ) and serum hepcidin (CERA vs. DPO; $P=$ 0.063 ) did not differ significantly between CERA and DPO administration.

\section{Discussion}

We recently reported that the suppressive effect of serum hepcidin and ferritin was significantly stronger by DPO than short-acting rHuEPO [6]. Therefore, to confirm the superiority of DPO on iron utilization, we made the study design to treat the enrolled patients firstly with DPO and then secondly with CERA in Japanese hemodialysis patients.

In the present study, all enrolled patients who require $3000 \mathrm{IU}$ of rHuEPO three times a week to keep the target $\mathrm{Hb}$ level seem to have a relatively ESA-resistant property. However, to elucidate whether DPO or CERA might be better in terms of iron utilization, it seemed more appropriate to examine their effect in the patients with a relatively ESA-resistant property.

Although CERA administration (single dose of $75 \mu \mathrm{g}$ on day 0 during 14 days of treatment) was no less potent than DPO administration (single dose of $40 \mu \mathrm{g}$ on each of day 0 and day 7 during 14 days of treatment) in the 


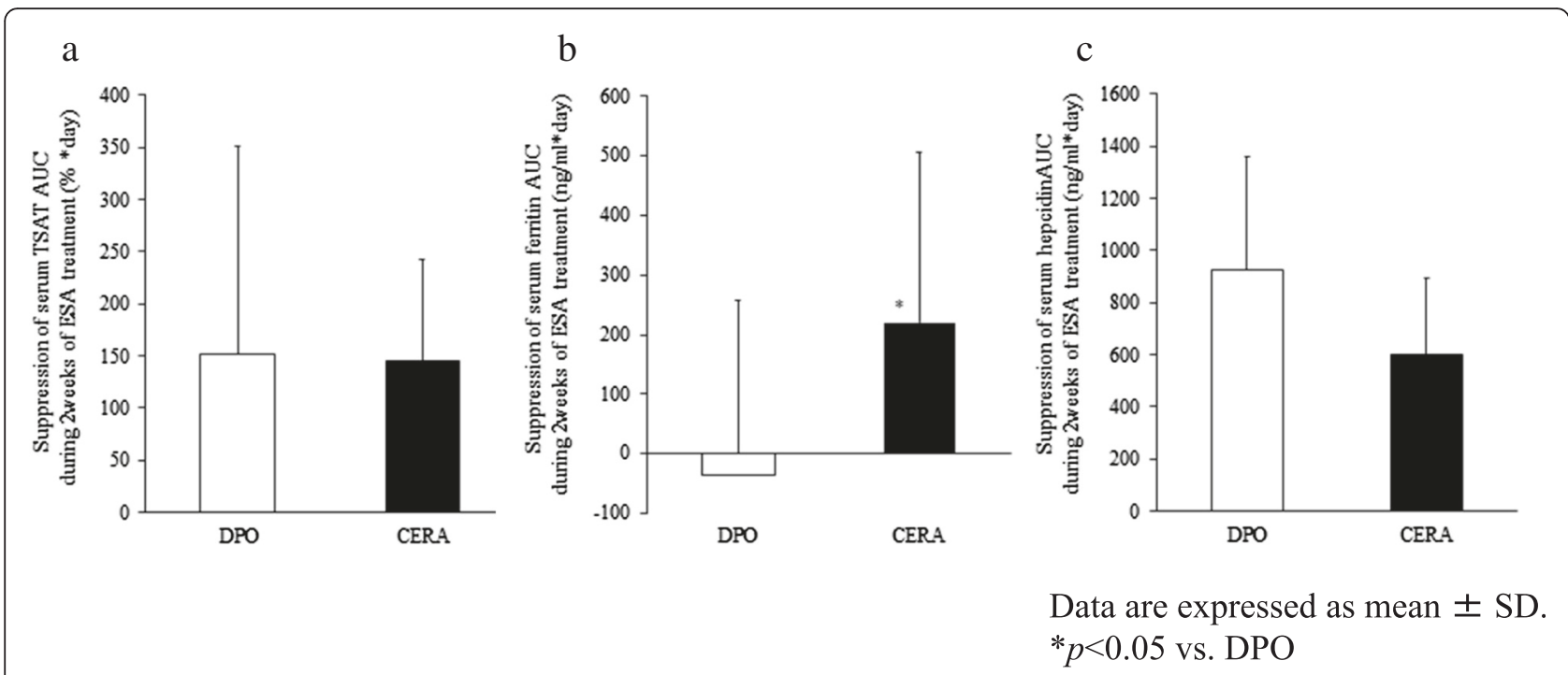

Fig. 2 Effects of each ESA in the suppression of TSAT (a), serum ferritin (b), and serum hepcidin (c) are estimated from the area under the respective curve during the 14 days of treatment period. Data are expressed as mean $\pm \mathrm{SD},{ }^{*} p<0.05$ vs. DPO

suppression of hepcidin, ferritin and TSAT by 9 days, these parameters began to increase by 14 days after single administration of $75 \mu \mathrm{g}$ CERA. However, based on the AUC during 14 days of CERA and DPO treatment, the effects of CERA to suppress serum hepcidin and TSAT did not differ significantly from those of DPO, although CERA was more potent than DPO in the suppression of serum ferritin.

Because of the time-course of serum hepcidin, it is conceivable that the erythropoietic activity of CERA might be diminished after 9 days of CERA administration, while the erythropoietic activity of DPO remained persistent throughout 7 days of DPO administration. The greater potency of CERA in the suppression of serum hepcidin on day 7 might lead to the significant suppression of serum ferritin. Conversely, an increase of serum hepcidin in the CERA-treated group might be associated with significant increase of serum ferritin (Fig. 1). However, during the 14 days of treatment period, it was suggested that the effect of CERA might have greater potency than DPO to suppress serum ferritin, in contrast with the insignificant difference in the potencies to suppress serum hepcidin between two ESAs.

It has been previously reported that serum ferritin might be reduced as the ESA efficiently improves anemia by suppressing serum hepcidin to increase iron movement from the body iron store into circulation [11]. In the present study, DPO administration significantly increased the hemoglobin level, while CERA administration did not significantly affect the hemoglobin level during the treatment period of 14 days. However, as shown in Fig. 2, the suppression of serum ferritin was significantly greater during CERA administration than
DPO administration, while serum hepcidin did not differ significantly between CERA and DPO administration. Therefore, our result suggested that CERA might be a more superior ESA in iron utilization.

In hemodialysis patients, iron supplementation, which might compensate for the iron loss due to blood loss into the dialysis circuit during each hemodialysis session, is essential in treating anemia and to increase the EPO responsiveness to ESA dosage [12, 13]. However, iron overload may increase oxidative stress [14] and leave patients at risk for infection [15], arteriosclerosis [16], and viral hepatitis [17]. Furthermore, we have recently reported that administration of intravenous iron in hemodialysis patients increases the all-cause mortality in a dose-dependent manner, which is independent of serum TSAT and ferritin levels, suggesting that iron alone might directly exert a harmful effect in hemodialysis patients [18].

Serum ferritin level, which represents total body iron stores, might provide a relevant measure for the risk of infection and cardiovascular events, as well as mortality in hemodialysis patients [19]. In patients undergoing hemodialysis, it has been shown that a higher serum ferritin level is associated with a high incidence of bacteremia [20] and a reduction in the phagocytic ability of leukocytes [21]. Previous studies have additionally shown that a high serum ferritin level is associated with hospitalization, morbidity, and an all-cause mortality in hemodialysis patients [22, 23].

In Japan, since the harmful effect of iron has long been advocated to iron-usage restriction, we reported that intravenous administration of iron is significantly lower in Japan than other countries [24]. 
As the harmful effect of iron overload becomes more widely appreciated, guidelines for renal anemia in chronic kidney disease released by the Japanese Society for Dialysis Therapy [5] recommended that serum ferritin levels in hemodialysis patients should be kept lower [25].

Serum hepcidin regulates the cellular iron exporter protein ferroportin and is therefore recognized as the rate-limiting factor in the mobilization of iron across cell membranes and into circulation [26]. There is a positive correlation between serum levels of ferritin and hepcidin, indicating that high serum ferritin levels reduce the overall supply of iron into the circulation available for erythropoiesis [11]. Indeed, a study examining the correlation between serum hepcidin level and prognosis in patients undergoing hemodialysis has shown that patients with high serum hepcidin frequently experience cardiovascular events [27], indicating that serum hepcidin is likely a useful index for cardiovascular risk independent of serum ferritin.

It is recently reported that erythroferrone, produced by erythroblast in response to EPO [8], suppressed hepcidin production during hematopoiesis to increase the utilization of iron for bone marrow erythropoiesis. Therefore, it is theoretically assumed that the potency of ESAs to increase erythroblastosis should be negatively associated with their effect to suppress serum hepcidin.

In this study, there were no significant differences of erythropoietic activity and the suppression of hepcidin between CERA and DPO administrations. It is possible that the greater suppressive effect of CERA on serum ferritin might be a more potent effect of CERA in the utilization of iron for erythroblastosis.

There are several limitations in the present study. First, this study is an open label, single arm trial. Second, CERA was injected only once, so it might not represent a stable response to this agent. Furthermore, the number of patients was rather small, and the observation period was short to elucidate the true phenomenon.

Therefore, although the suppressive effect of CERA on serum ferritin seemed greater than that of DPO from the present study, it is yet to be concluded whether the effect of CERA might be more potent than that of DPO from the standpoint of iron utilization.

\section{Conclusions}

The effect of CERA administered once every 2 weeks exhibited no less potent effect in terms of iron utilization than that of DPO administered every week.

\section{Competing interests}

The authors declare that they have no competing interests.

\section{Authors' Contributions}

JS designed and performed the study, analyzed the data, and wrote the paper. KN, CN, MK, Y Kuwamura, NW, KK, Y Kawaguchi, and Y Kumeda performed the study and acquired the laboratory data with JS. Y Kumeda participated in the study design and performed the statistical analysis with JS. MI conceived the ideas of the study, participated in its design and coordination, and helped to draft the manuscript. All authors discussed the results and implications and commented on the manuscript at all stages. All authors contributed extensively to the work presented in this paper.

\section{Acknowledgements}

We thank Prof. Naohisa Tomosugi (Kanazawa Medical University, Ishikawa, Japan) for kindly providing support to measure hepcidin-25. We thank the patient subjects, staff, and physicians for their cooperation in participating in this study.

\section{Author details}

${ }^{1}$ Department of Internal Medicine, Minami-Osaka Hospital, Osaka, Japan. ${ }^{2}$ Department of Metabolism, Endocrinology and Molecular Medicine, Osaka City University Graduate School of Medicine Osaka, Osaka, Japan. ${ }^{3}$ Department of Nephrology, Osaka City University Graduate School of Medicine Osaka, Osaka, Japan.

Received: 2 September 2015 Accepted: 28 March 2016

Published online: 29 June 2016

\section{References}

1. Macdougall IC, Eckardt KU. Novel strategies for stimulating erythropoiesis and potential new treatments for anemia. Lancet. 2006;368:947-53.

2. Brunkhosrst $\mathrm{R}$, Bommer J, et al. Darbepoetin alfa effectively maintains hemoglobin concentrations at extended dose intervals relative to intravenous or subcutaneous recombinant human erythropoietin in dialysis patients. Nephrol Dial Transplant. 2004;19:1224-30.

3. Levin NW, Fishbane S, Cañedo FV, Zeig S, Nassar GM, Moran JE, et al. Intravenous methoxy polyethylene glycol-epoetin beta for hemoglobin control in patients with chronic kidney disease who are on dialysis: A randomized non-inferiority trial (MAXIMA). Lancet. 2007;370:1415-21.

4. Canaud B, Mingardi G, Braun J, Aljama P, Kerr PG, Locatelli F, et al. Intravenous C.E.R.A. maintains stable hemoglobin levels in patients on dialysis previously treated with darbepoetin alfa: results from STRIATA, a randomized phase III study. Nephrol Dial Transplant. 2008;23:3654-61.

5. Shoji S, Inaba M, Tomosugi N, et al. Greater potency of darbepoetin-a than erythropoietin in suppression of serum hepcidin-25 and utilization of iron for erythropoiesis in hemodialysis patients. Eur J Hematol. 2013;90:237-44.

6. Tsubakihara Y, Nishi S, Akiba T, et al. 2008 Japanese Society for Dialysis Therapy: guidelines for renal anemia in chronic kidney disease. Ther Apher Dial. 2010;14(3):240-75.

7. Sasaki Y, Noguchi-Sasaki M, Yasuno H, Yorozu K, Shimonaka Y. Erythropoietin stimulation decreases hepcidin expression through hematopoietic activity on bone marrow cells in mice. Int J Hematol. 2012; 96:692-700

8. Kautz L, Jung G, Valore EV, Rivella S, Ganz T. Identification of erythroferrone as an erythroid regulator of iron metabolism. Nat Genet. 2014;46(7):678-84.

9. Murano N, Ishigai M, Yasuno H, Shimonaka Y, Aso Y. Simple and sensitive quantification of bioactive peptides in biological matrices using liquid chromatography/selected reaction mass spectrometry coupled with trichloroacetic acid clean-up. Rapid Commun Mass Spectrom. 2007;21:4033-8.

10. Maekawa K, Shoji T, Emoto M, Okuno S, Yamakawa T, Ishimura E, et al. Influence of atherosclerosis on the relationship between anaemia and mortality risk in haemodialysis patients. Nephrol Dial Transplant. 2008;23:2329-36.

11. Van der Putten $K$, Jie KE, Van den Broek $D$, et al. Hepcidin-25 is a marker of the response rather than resistance to exogenous erythropoietin in chronic kidney disease/chronic heart failure patients. Eur J Heart Fail. 2010;12:943-50.

12. Rozen-Zvi B, Gater-Gvili A, Paul M, et al. Intravenous versus oral iron supplementation for the treatment of anemia in CKD: systematic review and meta-analysis. Am J Kidney Dis. 2008;52(5):897-906.

13. Albaramki J, Hodson EM, Craig JC, et al. Parenteral versus oral iron therapy for adults and children with chronic kidney disease. Cochrane Database Syst Rev. 2012;1, CD007857.

14. Anraku M, Kitamura K, Shinohara A, et al. Intravenous iron administration induces oxidation of serum albumin in hemodialysis patients. Kidney Int. 2004;66:841-8.

15. Kalantar-Zadeh K, Regidor DL, McAllister CJ, et al. Time-dependent associations between iron and mortality in hemodialysis patients. J Am Soc Nephrol. 2005;16:3070-80. 
16. Drueke T, Witko-Sarsat V, Massy Z, et al. Iron therapy, advanced oxidation protein products, and carotid artery intima-media thickness in end-stage renal disease. Circulation. 2002;106:2212-7.

17. Kato A, Odamaki M, Nakamura $\mathrm{H}$, et al. Elevation of blood thioredoxin in hemodialysis patients with hepatitis C virus infection. Kidney Int. 2003;63: 2262-8.

18. Bailie GR, Larkina M, Goodkin DA, Li Y, Pisoni RL, Bieber B, et al. Data from the Dialysis Outcomes and Practice Patterns Study validate an association between high intravenous and mortality. Kidney Int. 2015;87(1):162-8.

19. Kuragano T, Matsumura O, Matsuda A, et al. Association between hemoglobin variability, serum ferritin levels, and adverse events/mortality in maintenance hemodialysis patients. Kidney Int. 2014;86:845-54.

20. Boelaert JR, Daneels RF, Schurgers ML, et al. Iron overload in haemodialysis patients increases the risk of bacteraemia: a prospective study. Nephrol Dial Transplant. 1990:5:130-4

21. Patruta SI, Edlinger R, Sunder-Plassmann G, et al. Neutrophil impairment associated with iron therapy in hemodialysis patients with functional iron deficiency. J Am Soc Nephrol. 1998;9:655-63.

22. Kletzmayr J, Horl WH. Iron overload and cardiovascular complications in dialysis patients. Nephrol Dial Transplant. 2002;17(2):25-9.

23. Kalantar-Zadeh K, Don BR, Rodriguez RA, et al. Serum ferritin is a marker of morbidity and mortality in hemodialysis patients. Am J Kidney Dis. 2001;37:564-72

24. Akizawa T, Pisoni RL, Akiba T, Saito A, et al. Japanese haemodialysis anaemia management practices and outcomes (1999-2006): results from the DOPPS. Nephrol Dial Transplant. 2008;23(11):3643-53.

25. Hasuike $Y$, Nonoguchi $H$, Tokuyama $M$, et al. Serum ferritin predicts prognosis in hemodialysis patients: the Nishinomiya study. Clin Exp Nephrol. 2010;14:349-55.

26. Nemeth E, Tuttle MS, Powelson J, Vaughn MB, Donovan A, Ward DM, et al. Hepcidin regulates cellular iron efflux by binding to ferroportin and inducing its internalization. Science. 2004;306:2090-3.

27. Van der Weerd NC, Grooteman MP, Bots ML, et al. Hepcidin-25 is related to cardiovascular events in chronic haemodialysis patients. Nephrol Dial Transplant. 2013:28:3062-71.

\section{Submit your next manuscript to BioMed Central and we will help you at every step:}

- We accept pre-submission inquiries

- Our selector tool helps you to find the most relevant journal

- We provide round the clock customer support

- Convenient online submission

- Thorough peer review

- Inclusion in PubMed and all major indexing services

- Maximum visibility for your research

Submit your manuscript at www.biomedcentral.com/submit

) Biomed Central 